\title{
An Overview of Ocean Pollution
}

\author{
Ruchira Shinde $^{1}$, Sagar Gawande ${ }^{2}$ \\ ${ }^{1}$ ME Student, Civil Environmental Engineering, APCOER, Pune, Maharashtra, India \\ ${ }^{2}$ Associate Professor, Civil Engineering Department, APCOER, Pune, Maharashtra, India
}

\begin{abstract}
It is said that money can compensate everything, but this a wrong presumption which is proved by the ever increasing pollution in the sea which is destroying the marine life and thus disturbing the whole ecological balance. This paper briefly gives an overview of the ocean pollution and also the impacts created on humans and the aquatic life. In today's advancing era, oceans are the main source for dumping many types of waste such as plastic, oil waste, waste water. For the many years trash is dumped in the ocean causing death of variety of aquatic flora and fauna leading to the extinction of many species of fishes. Millions of animals, including birds, fishes which are solely dependent on water, are killed as a direct consequence of pollution. Other types of oceanic pollution such as oil spills and radioactive and industrial waste, pollution due to festivals are just as costly and can contaminate the oceans for thousands of years to come. This pollution is having hazardous effects like creation of dead zones in various parts of the ocean causing death of depletion of oxygen in the water. If we humans do not curtail our way of living as a token of respect towards oceans, the damage will be irreversible thus causing permanent damages to the environment.
\end{abstract}

Keywords: Dead Zones, Marine Pollution, Festivals, Humans

\section{Introduction}

Oceans form the largest water body in the world. Ocean pollution is mainly due to humans caused by a variety of factors such as festivals like Narali Pounima, Ganesh Visarjan, deposition of waste water in to the sea without treatment and many other reasons. This pollution is ignored for many years and the problem has hence become a major issue in today's era.

At one point of time people thought that the vastness of the ocean will dilute the pollutants to eliminate their impacts. But these pollutants hazardously alter the balance of ecosystem.

This pollution has costs in a many variety ways tourism revenue, coastal economic activities, and lost resources.

On an individual level, these have dangerous effects on marine animals and plants resulting in the extinction of many aquatic animals.

Oceans provide home to a variety of lives, and hence it is responsibly of every citizen to play its part in avoiding pollution in the sea and hence helping the marine life to thrive for long.

\section{Causes of Ocean Pollution}

Varieties of factors are responsible for ocean pollution. Further are some of the major components contributing towards sea pollution,

\subsection{Dumping of Garbage on the sea-shore:}

Garbage like water bottles and other waste floating matter on the beaches are the solid proof of people's impact on the ocean. Such trash is often dumped along the sea shore which ends up getting inside the sea along with waves. Also Industrial waste is one of the big issues when it comes to ocean dumping. These chemicals are toxic which include, radioactive chemicals which are dangerous effects on the marine life.

Effects of Dumping: Marine debris mainly has a direct hazard to the aquatic life. With the reduction in aesthetic value, it affects the tourism Marine debris is both an aesthetic issue and a direct hazard to marine life. With undesirable changes in beach areas, the economies of coastal communities may be significantly affected by a loss in tourism revenue.

Debris with sharp edges also poses a danger to beachgoers, swimmers, divers, and boaters.

In addition to aesthetic problems, engulping of marine debris and entanglement in debris can harm sea birds, marine mammals, and other sea life. Entrapment and ingestion may lead to death if the animal is not able to move, consume food, and avoid predators. Many marine species are already threatened or endangered, and the effects of debris only make matters worse.

Marine animals like Sea turtles mistake plastic bags for jellyfish and die from internal blockages.

There are huge areas of garbage that are sometimes referred to as islands of garbage. The garbage is not only confined to the surface. The material that is too heavy to float ends up on the bottom. This foreign matter present in the environment disrupts aquatic flora as well as fauna.

Birds, fish and large sea creatures mistake plastics and other garbage for food. Plastics get into the animals' digestive systems. Plastics tend to absorb chemicals causing a concentration of toxins which goes up the animal chain. Larger creatures eat smaller ones and ultimately, some are consumed by humans. By this means, these toxins can end up in our bodies. Animals who are most often the victims of plastic debris include turtles, dolphins, fish, sharks, crabs, sea birds, and crocodiles. 


\section{International Journal of Science and Research (IJSR) \\ ISSN (Online): 2319-7064 \\ Index Copernicus Value (2013): 6.14 | Impact Factor (2014): 5.611}

2.2 Oil Spills ${ }^{[13]}$ : Oil is one of the most visible and commonly discussed types of ocean pollution. Oil in the ocean includes crude oil, refined petroleum products such as gasoline or oily refuse. The main natural source of oil in the ocean is seepage, where crude oil oozes into the water from geologic formations beneath the sea floor. Man - made causes include petroleum use, including tanker spills, occasionally, offshore drilling rigs experience accidental leaks. Ships carrying oil cause devastating oil spills, but these are large-scale disasters. One of the greatest sources of oil pollution is people who pour various cooking oils and grease down the sink drains in their homes.

Effects of Oil Spills: Oil pollution affects ocean ecosystems most significantly by endangering aquatic life. Floating on top of the water's surface, oil coats the wings and feathers of marine animals.

Oil-soaked plumage makes birds less buoyant, reduces their insulation, and increases their vulnerability to temperature fluctuations. It also impairs flight ability such that they cannot forage for food or escape from predators. When birds attempt to clean off their feathers, they often ingest the oil, causing kidney damage, altered liver function, and digestive tract irritation. This may lead to death through organ failure, impaired digestion, or dehydration

Marine mammals like otters and seals are left unable to regulate body temperature when their insulating fur is coated in oil, leading to hypothermia.

In addition, oil floating on top of seawater reduces light penetration, limiting the photosynthetic activities of the marine plants and phytoplankton that form the base of the ecosystem. This in turn affects sources of nutrition for other organisms higher on the food chain. Spilled oil also spreads onto beaches, marring the landscape and inhibiting recreational uses like bathing and kayaking. Substances evaporating from oil can irritate the skin, eyes, and respiratory systems of humans.

\subsection{Sewage/ Fecal Waste}

Animal waste and human wastewater from toilets and other household activities such as bathing and laundering as well as food preparation are often washed directly into the ocean from coastal communities. Raw sewage collected from toilets and other household wastewater contains everything from infectious bacteria and viruses to toxic chemicals and nutrients.

Effects of Sewage: Direct exposure to sewage can cause rashes, earaches, stomach-aches, pink eye, diarrhoea, vomiting, respiratory infections, hepatitis, encephalitis, and typhoid.

Sewage contains chemicals that alter the marine environment, causing some marine life to die and other marine life to flourish. This throws off the natural balance of marine ecosystems.
Sewage can also deprive marine environments of oxygen, killing off entire populations in affected areas.

\subsection{Heavy Metals}

Heavy metals are natural components of the Earth's crust. Trace amount of some metals like cobalt, copper and zinc are necessary for maintaining metabolic functions. Excess of this can have detrimental effects. Metals like Mercury, Lead and Cadmium have severe adverse impacts. Heavy metals possess toxic substances, since they are non-degradable, they bio accumulate and they produce acute or chronic toxic effects. These metals find their way into the marine environment either through river influx or atmospheric deposition; direct discharges from industrial sources.

Effects of Heavy Metals ${ }^{[3]}$ : Toxicity and adverse health effects vary widely depending on the type of metal: for instance, while some forms of mercury, even if absorbed in small doses, cause severe damage to the brain and the central nervous system, short-term exposure to nickel does not produce any effect while long-term exposure may cause skin irritation or liver damage

Copper is dangerous to marine organisms and has been used in marine anti-fouling paints.

\subsection{Toxic Chemicals}

Industrial and agricultural waste are another most common form of wastes that are directly discharged into the oceans, resulting in ocean pollution. The dumping of toxic substances in the ocean directly affects the marine life as they are considered hazardous. Rain water often picks up small amounts of toxic chemicals from agricultural fields, lawns, roads, and parking lots and carries them directly to the ocean through storm drains. Pharmaceutical, industrial, agricultural, personal care, household cleaning, gardening, and automotive products and wastes still down onto lakes, rivers, and the ocean. Once deposited in ocean sediments, mercury ends up in sediments, fish, and other animals, or volatilizes back into the atmosphere.

Effects of Toxic chemicals: They raise the temperature of the ocean, known as thermal pollution, as the temperature of these liquids is quite high. Animals and plants that cannot survive at higher temperatures eventually perish.

The decimation of brown pelican populations due to release of DDT in the environment, its bioaccumulation, and the resultant eggshell thinning is a good example of the harmful potential of toxic pollutants.

One type of emerging contaminant is endocrine disruptors. Endocrine disruptors are substances that act like hormones in the bodies of human and animals, thus interfering with normal activity in the endocrine system. Many detergents, pesticides, plastics, and varnishes, for example, are derived from or contain endocrine disrupting chemicals. Exposure to sufficient quantities of these chemicals could theoretically cause unnatural developmental and reproductive changes. In 


\section{International Journal of Science and Research (IJSR) \\ ISSN (Online): 2319-7064 \\ Index Copernicus Value (2013): 6.14 | Impact Factor (2014): 5.611}

some controlled experiments, they were shown to alter sex determination and dynamics of fish populations.

\subsection{Nutrients}

Owing to nutrients released on land, for instance from livestock waste, household detergents, lawn care products, and crop fertilizers, oceans are over-fertilized in many coastal regions around the globe. Nutrients from these and other sources tend to get concentrated in storm runoff, rivers, and water treatment plant effluent. Much of this water flows downhill and eventually releases into lakes or oceans, leading to a localized area at the discharge point where nutrient concentrations are elevated. This imbalance may then instigate a string of negative effects in a process called "eutrophication".

\section{Effects of Nutrients}

1)Eutrophication is an increase in the production of organic matter through algal blooms or aquatic plants. If too much nitrogen and phosphorus find their way into the ocean, these nutrients fertilize an explosive growth of algae.

2)When the masses of algae die and sink to the bottom, their decomposition consumes most of the oxygen in the water. The resulting lack of oxygen can wipe out marine life across the entire affected area.

3)Algal blooms contribute to loss of endangered sea grass beds and coral reefs by clouding water, cutting off sunlight, and essentially smothering coral.

4)Oxygen levels drop so low in the spring and summer that most fish and shellfish cannot survive, creating what is known as a "dead zone."

5)Fish, shrimp, and crabs flee the area while less mobile bottom-dwellers such as snails, clams, and starfish may die. This phenomenon occurs yearly and is attributed to excess nutrients, mostly from fertilizer-rich runoff.

6)Additionally the temperature of the ocean is highly affected by carbon dioxide and climate changes, which impacts primarily the ecosystems and fish communities that live in the ocean. In particular, the rising levels of $\mathrm{CO}_{2}$ acidify the ocean in the form of acid rain. Even though the ocean can absorb carbon dioxide that originates from the atmosphere, the carbon dioxide levels are steadily increasing and the ocean's absorbing mechanisms, due to the rising of the ocean's temperatures, are unable to keep up with the pace.

\subsection{Ocean Mining}

Ocean mining in the deep sea is yet another source of ocean pollution. Ocean mining sites drilling for silver, gold, copper, cobalt and zinc create sulfide deposits up to three and a half thousand meters down in to the ocean.

Effects of Ocean Mining: Deep sea mining causes damage to the lowest levels of the ocean and increase the toxicity of the region. This permanent damage dealt also causes leaking, corrosion and oil spills that only drastically further hinder the ecosystem of the region.

\subsection{Sunscreen}

Sunscreen is a lesser known source of pollution, but can have grave effects. The chemicals in sunscreen worn by swimmers and divers wash off into the ocean water and coats plant-life on coral reefs and suffocate them. Vast swaths of reefs have been destroyed, but there are eco-friendly sunscreen products on the market that help to prevent this terrible side-effect, while still protecting skin from cancerous sunrays

\subsection{Land Runoff}

Land runoff is another source of pollution in the ocean. This occurs when water infiltrates the soil to its maximum extent and the excess water from rain, flooding or melting flows over the land and into the ocean. Often times, this water picks up man-made, harmful contaminants that pollute the ocean, including fertilizers, petroleum, pesticides and other forms of soil contaminants. Fertilizers and waste from land animals and humans can be a huge detriment to the ocean by creating dead zones.

\subsection{Pollution due to festivals in India ${ }^{[8}$}

Festivals like Ganesh Chaturthi, Durga Puja, Diwali, and Holi are occasions for great joy and celebrations across our country. With we celebrating these festivals, also call for a disaster. Pollution of various types is generated in large amounts all across the country, thereby adding an even greater load pollutants and contaminants to our already over polluted environment, overburdened rivers, lakes, and seas.

Festivals like Ganesh Chaturthi and Durga Puja involve immersion of idols into water bodies. The practice of immersion has become a growing cause for concern on account of its adverse environmental impacts, particularly on the water bodies. Toxic exposure of the larger community through deadly chemicals and heavy metals used for making idols is a matter of concern.

The festivities surrounding Ganesh Chaturthi and Durga Puja culminate with idols being immersed in various ponds and lakes, painting a picture of ecological disaster. Thus the problem is spread countrywide. Immersion of idols in these natural aquatic ecosystems destroys the whole ecological balance.

After examining the water before and after immersion it was found that the concentration of substances like calcium, magnesium, molybdenum and silicon concentrations increased significantly. Also, it was found that concentrations of heavy metals like arsenic, lead and mercury had increased. Metals like lead and mercury are particularly hazardous as they are dangerous to health and can damage the heart, kidneys, liver, circulatory system and central nervous system. The other pollutant besides metals which is added is POP (Plaster of Paris). Immersion of POP idol into the water increases its hardness which deteriorates the quality of water. The major exposure route is through inhalation, ingestion, skin and eye contact and common symptoms are watering of eyes, skin irritation, and trouble in breathing incessant 


\section{International Journal of Science and Research (IJSR) \\ ISSN (Online): 2319-7064}

Index Copernicus Value (2013): 6.14 | Impact Factor (2014): 5.611

coughing affecting organs like eyes, skin, and respiratory system.

\section{Effects on Water Quality}

The water bodies are in a very poor state every year after Ganesh and Durga puja is over. Along with idols flowers, banana leaves, coconuts etc are immersed in various water bodies, resulting in alarming increase in pollution levels. It is mainly caused by dissolution of wastes coming from silting of clay, Plaster of Paris and the cheap toxic coloured paints (chemical dyes), painted on the idols which comes in contact with water. Once these idols are immersed, the clay along with Plaster of Paris (Calcinated Gypsum) slowly dissolve and accumulate at the bottom of the water body, whereas the toxic paints form a thin film on the surface of water. This cuts down the oxygen supply for aquatic animals and fish as decomposition of organic wastes uses oxygen in water making it impossible for aquatic animals to survive.

\subsection{Radioactive Materials}

The most significant inputs of radioactive materials into the marine environment originate from nuclear industry activities and the dumping of radioactive waste. Present day levels of radioactive substances found in coastal waters are the result of natural and possibly released radioactivity due to human activities such as oil exploration and combustion, phosphate production and use, land-based mining, managed discharges from nuclear power and reprocessing facilities, fallout from atmospheric nuclear weapons testing and accidents, medical diagnosis and therapy, and food conservation.

Radioactive waste enters the ocean from nuclear weapon testing and the resulting atmospheric fallout, the releasing or dumping of wastes from nuclear fuel cycle systems, and nuclear accidents.

\subsection{Noise}

Many species of marine mammals, as well as some other aquatic species, sound is a primary sensory means of communicating, navigating, and foraging. The ocean environment has always included an abundance of natural noises, such as the sounds generated by rain, waves, earthquakes, and other animals. However, a growing number of ships, oil exploration activities, and military and civilian sonar use add to the ambient noise in the oceanic environment.

Human-generated sound in the ocean comes from a variety of sources, including commercial ship traffic, oil exploration and production, construction, acoustic research, and sonar use. Noise is also an unintentional by-product of coastal and marine construction, ship propellers, mineral extraction, and aircraft flights. Mine-hunting sonars, fish finders, some oceanographic systems (such as acoustic Doppler current profilers), and high-resolution seafloor mapping devices can create noise at a higher frequency.

\section{Effects of Noise}

Noise can have a detrimental effect on animals by causing stress, interfering with the ability to detect prey and avoid predators, and impairing communication needed for reproduction and navigation. Noise may also force animals into smaller areas of habitat. Exposure to high levels of noise could even lead to permanent hearing loss.

\section{Effects of Ocean Pollution}

Control of pollution is of paramount importance because of its alarming consequences. Oceans are very important for maintaining the overall balance of eco-system. Following are some of the steps to control marine pollution:

\subsection{General Aspects}

Preventing marine pollution is very important for the wellbeing of the sea, the marine life it supports and humans! Cleaner oceans means prevention of aesthetics, beaches for swimming, fishing and recreation. There are a lot of things we can each do to make a difference, either on your own or in a group, to make a huge difference:

1) Organizing a beach clean-up.

2)Reducing rubbish and using recyclable materials as far as possible.

3)Take care of a local stream.

\subsection{Large Scale Solutions for Ocean Pollution:}

It's very difficult to clean up pollution once it has occurred, so the best way is prevention:

- Stricter government regulations or standards on industry and manufacturing

- Avoiding off-shore drilling as far as possible.

- Limit agricultural pesticides

- Proper sewage treatment

- Cut down on waste and contain landfills

- Carry a reusable shopping bag instead of plastic bags

- Store food in reusable containers instead of those you throw away

- Avoid products that come with excess packaging

- Don't litter

\subsection{Technical Aspects:}

a) Waste treatment: The waste treatment include treating of the waste coming from industries and factories before it is left off itno the sea or any other water bodies. This can be done by various treatment processes, methods of pollution control, ultimate disposal and recycling of waste.

b) Sewage and industrial waste: Many industrial wastes differ markedly in chemical composition and toxicity from domestic sewage. They often contain persistent or refractory organics which resist secondary treatment procedures that are normally applied to domestic sewage.

There is a need for improved methods of treatment for industrial wastes.

- Reducing overboard discharge of waste

- Establishing safe standards on waste effluent

- Providing safety standards for offshore activities 


\section{International Journal of Science and Research (IJSR) \\ ISSN (Online): 2319-7064 \\ Index Copernicus Value (2013): 6.14 | Impact Factor (2014): 5.611}

c) Oil waste: There should be facilities for the receiving and treatment of oily waste mixtures separately.

d) Thermal waste: The present treatments are cooling ponds, cooling tower (not economical) and direct discharge into receiving water. The needs for new methods of cooling and the development of beneficial use are urgent

e) Radioactive wastes: These cannot be treated biologically or by oxidative treatment. The present disposal approaches are: concentration and containment: The procedures are treatment, storage, container (steel and concrete) transportation and handling equipment for dumping.

The major concerns in nuclear waste disposal are:

- Possibility of the return of radioactivity to man

- Possibility of severely altering the biological balance of the ocean

- Interference with other uses of the sea.

The dumping practice: Dumping in deep trenches is not recommended. The present design for waste containers is, for ten years life expectancy. They are exposed to the danger of being burst out due to the terrific pressure and the buffeting by currents.

f) Improvement in ship design and navigation system:

The needs for improved ship design are:

- Consideration of pollution prevention measures in ship design

- Adequately trained crews feasibility of shore-based guidance system.

g) Surveillance: Water quality monitoring system: developing methods of detection and surveillance of pollution.

- Developing methods of tagging pollutants

- Developing in site monitoring devices

- Establishing information on hazardous cargoes such as their movement, cargo properties and emergency control methods.

- Survey of coast area

- Improvement of handling and storage of the dangerous cargoes

h) Safety on the continental shelf: review design practices of offshore ports to accommodation of super tankers.

- Study of transfer facilities, such as pipelines, artificial islands, isolated shore locations, ship to barge transfer, ocean barge systems, and submarine tankers.

- Minimizing conflicts among the various activities including shipping transfer of liquid or gases in pipelines, fishing, recreation, and drilling, pumping and storing materials underwater or at the surface.

- Elimination of wrecks, debris and litter.

\section{Conclusion}

Ocean pollution brings lot problems into highlight the complicated problems faced by humans as well as the animals and the environment which are created by the human beings. It is high time to understand the humans should understand the importance of ocean. Oceans form the main part of the main part of the ecological cycle. They form shelter to a thousand of living beings.

Since the networks of oceans are interconnected efforts are needed to be a taken at an international level for the conservation of ocean.

Since the main factors for the pollution are the we human beings, it is necessary that we humans curtail our ways of living and each one of us should get involved to find a solution

In short, in order to preserve \& protect the coastal environment legal and responsible application of scientific knowledge on all aspects of pollution is essential

It should be known that everything cannot be compensated by money. However in truth the any nature damages cannot be compensated and results in long term and permanent damages on the environment.

\section{References}

[1] https://en.wikipedia.org/wiki/Marine_pollution. A Literature Survey of Ocean Pollution by H. H. ShihInstitute of Ocean Science and Engineering School of Engineering and Architecture the Catholic University of America Washington.

[2] Marine Invertebrates as Bio indicators of Heavy Metal Pollution-Roberto Chiarelli, Maria Carmela Roccheri Open Journal of Marine Science

[3] Pollution in the Bay of Bengal: Impact on Marine Ecosystem- Towhida Rashid, Sirajul Hoque, Sharmin Akter- Open Journal of Marine Science

[4] Impact of pollution on marine environment -A case study of coastal Chennai- A. Duraisamyand S. LathaIndian Journal of Science and Technology, Vol. 4 issue 3 (March 2011)

[5] Ocean Science Series, Pollution in the Ocean, the National Academics.

[6] Pollution in the Ocean- The Aquarium Of The PacificOcean On The Edge: Top Ocean Issues, May 2009.

[7] Environmental Pollution in Coastal Areas of India- R Sen Gupta, Sugandhini Naik and V. V. R. Varadachari, Ecotoxicology and Climate, Published by John Wiley \& Sons Ltd.

[8] Festivals: A Time of Celebration or Impending Environmental Disaster- Sujoy Chatterjee and Dr. Prashant Mehta

[9] State of the planet, Our Oceans- A Plastic soup, The Earth Institute, Columbia University

[10] Keeping World Environment Safer and Cleaner-Marine Pollution- By Partha Das Sharma.

[11] Marine Pollution and International Preventive Laws- A Case study of the Caribbean Sea by Rickey Jaggernath.

[12] Marine pollution - a perspective, monitoring and control in India - Dr. N.V.Vinithkumar, National Institute of Ocean Technology. 